\title{
Drug eluting sutures: A recent update
}

\author{
Anureet Arora1 ${ }^{1}$, Geeta Aggarwal ${ }^{2}$, Janita Chander ${ }^{1}$, Paramjot Maman $^{3}$, Manju Nagpal $^{1 *}$ \\ ${ }^{1}$ Chitkara College of Pharmacy, Chitkara University, Chandigarh Patiala National Highway, Patiala 140401, India. \\ 2Delhi Pharmaceutical Sciences and Research University, Govt. of NCT of Delhi, Pushp Vihar, Sector III, New Delhi 110017, India. \\ ${ }^{3}$ Paraxel Solutions Ltd, Rajiv Gandhi IT Park, Chandigarh, India.
}

\begin{tabular}{l}
\hline ARTICLE INFO \\
\hline Received on: $12 / 03 / 2019$ \\
Accepted on: 04/05/2019 \\
Available online: 01/07/2019 \\
\hline Key words: \\
Surgical, smart sutures, \\
ophthalmics, electrospinning, \\
antibacterial.
\end{tabular}

\begin{abstract}
The main use of surgical sutures is to assist closure and healing of trauma-induced as well as surgical wounds. This is done by upholding wound tissues together in order to facilitate the healing process. A huge variety of sutures are available for the medical purposes, e.g., bio active sutures, knot-less sutures, electronic sutures, drug-eluting sutures, anti-microbial sutures, and stem cells containing sutures. Sutures increase the capabilities to improve tissue approximation and wound healing. Sutures with drug eluting property are the advanced type of sutures being used for surgical purpose via delivery of drug to the specified area. Various new strategies develop the effectiveness of sutures to be used as physical entity to get better biologically active component which enables the delivery of various desirable drugs and cells to the affected site. Ideal modified sutures should not only retain its mechanical integrity during the healing process, but should also deliver the drugs loaded in it, in a controlled manner. These nano-structured fibers, produced by electrospinning and electrospraying techniques, offer tuneable release kinetics applicable to diverse biomedical applications. Drug eluting sutures lead to reduced surgical site infections, accelerated wound healing, reduced post-operative complications, and the most important thing is it reduces the need for supplement drugs. It will be the biggest achievement if we get the desired concentration and effect of the loaded drug in these sutures without affecting its mechanical properties. This can be achieved by enhancing/modifying the control release approaches. The current review gives updated information on recent advances in drug eluting sutures.
\end{abstract}

\section{INTRODUCTION}

Surgical suture or simply sutures are the medical devices, which are used for binding body tissues in the case of any medical apathy (Dennis et al., 2016). Suturing is done with the help of needle varying on the size, shape, and material of the suture. Sutures have a very wide use in medical field depending upon the requirement, i.e., dental, eye operations, other surgeries everywhere sutures are used (Saber, 2010). The sutures can be secured by using surgical knots. Looking from medieval era to present suture along with needles have seen a great changes, earlier needles used for suturing were made of bones or metals (copper, silver, aluminum, and

\footnotetext{
"Corresponding Author

Manju Nagpal, Chitkara College of Pharmacy, Chitkara University, Chandigarh Patiala National Highway, Patiala 140401, India. E-mail: nagpalmanju@ymail.com
}

bronze wire), and sutures were developed from plant parts (hemp, cotton, and flax) and animals parts (tendons, hair, arteries, nerves, muscle strips, catgut, and silk). The medieval data reports the use of sutures from past 3,000 BC in Egypt where suturing of mummy is reported in 1,100 $\mathrm{BC}$ (Mysore, 2012). Nowadays sutures are made synthetically like absorbable sutures (poly-dioxanone, poly-glycolic acid, monocryl polymer, and poly-lactic acid) as well as the non-absorbable (nylon, poly-ester, and poly-propylene) (Champeau et al., 2017). The absorbable sutures are fragmented by different methods, such as hydrolysis and proteolytic enzymatic degradation. The suture degradation depends upon its material varying from few days to weeks. The main use of absorbable suture is in the case where patient or doctor availability is not with ease and in case where internal body tissues are involved. The suturing of absorbable suture need to be done very carefully as the suture can cause to inflammation leading to rejection by human body (Hyde et al., 2012). Usually, non-absorbable sutures are mainly used 
in orthopedic surgery and cardiac surgery. These sutures can be removed after few weeks. The main advantage of non-absorbable sutures is that they cause less scars (Rooney, 2009). This is because of their less immune response and for this reason they are used for cosmetic outcome is mandatory.

The sizing of the sutures is based upon the guidelines of United State Pharmacopeia where originally the size ranged from 1 to 6 but due to the requirement of very fine suture, the size of suture was marked as $\# 00$ (\#2-0 or \#2/0) to $\# 000000$ (\#6-0 or \#6/0) but now the present suture vary from \#5 (heavy suture used in orthopedics) to \#11-0 (fine monofilament sutures used for ophthalmics). The most common technique for suturing is the simple interrupted stitch where knot is tied after every stitch (Dennis et al., 2016). The most common example of this is Caesarean section in case of uterine incision.

Various researchers are working on sutures to improve their effectiveness. It is indicated in various studies that active constituent can be added in sutures to make it drug eluting suture, which may be helpful in wound healing, tissue regeneration, treatment by stem cell, ophthalmic treatments, etc. (Kashiwabuchi et al., 2017). Various research reports on drug eluting sutures and their clinical applications have been covered in the following sections.

\section{Types of sutures}

Various upcoming sutures, such as antimicrobial, drug eluting, stem cell seeded, and electronic sutures are of recent research potential. Various upcoming sutures are listed in Figure 1 and the classification of sutures based on their physical and structural properties is shown in Figure 2.

\section{History of surgical drug eluting sutures}

Our daily life is significantly influenced by different types of polymeric materials. These polymeric materials play important role in various fields of packaging, such as food packaging, water purification, automobile industries, medical purpose, and pharmaceutical industries. Due to various superior and exceptional applications of polymeric substances and biomaterials, these are widely studied in medicine and pharmaceutical areas. These polymeric biomaterials have increased demand day by day in the synthesis of surgical sutures, surgical implants, and surgical scaffolds. This increased the demand of these polymeric biomaterials is because of their versatile nature as compared to the other ceramic and metallic materials. Various drug delivery systems, such as targeted drug delivery system, controlled drug delivery system, and slow and pulsatile drug delivery systems have been formulated by using these polymeric biomaterials. In the field of surgeries management and trauma management, sutures have been used very efficiently and effectively. The primary and main purpose of using sutures is that medical sutures have the ability to hold the damaged tissues so that they become together to each other which further facilitate and speed up the healing process without formation of scar or with minimum scar formation. Previously, various different types of materials were used in the manufacturing of pharmaceutically and medicinally used sutures, such as silver wires, iron wires, gold wires, steel wires, animal gut and hair, tree bark, silk, and various types of fibers obtained from different plants, such as linen and cotton. These days mostly synthetic polymeric biomaterials, such as poly (lactic-co-glycolic acid) (PLGA) (Huh et al., 2012) and poly-dioxanone (Ray et al., 1981) are used in the manufacturing of suture materials. Although there are various numbers of polymeric materials which can be used for manufacturing of sutures, there is not even a single suture material that can be used for all the types of the medical and surgical requirements. Hence, for most of the cases, the combinations of different types of polymeric materials are used in different required proportions in order to manufacture suture materials.

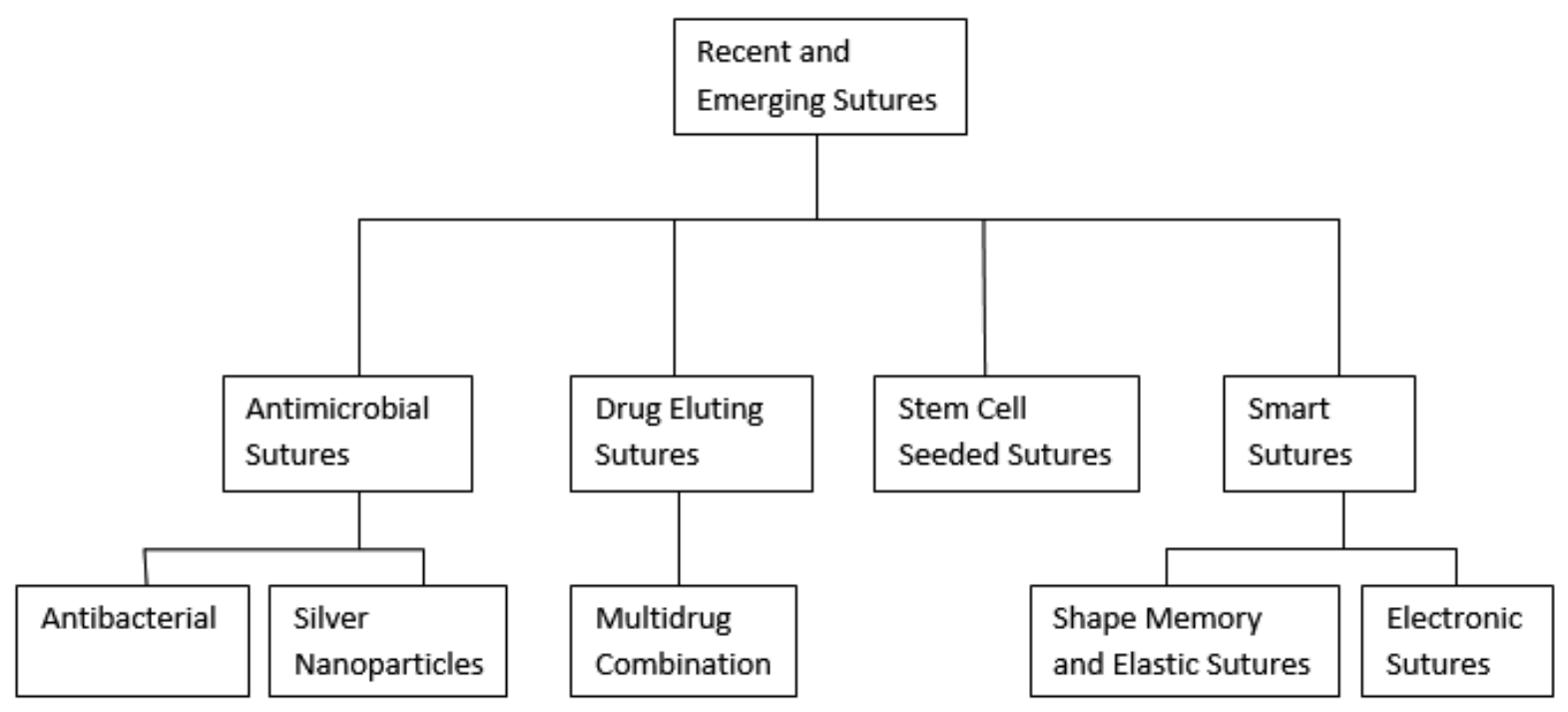

Figure 1. Various emerging sutures. 


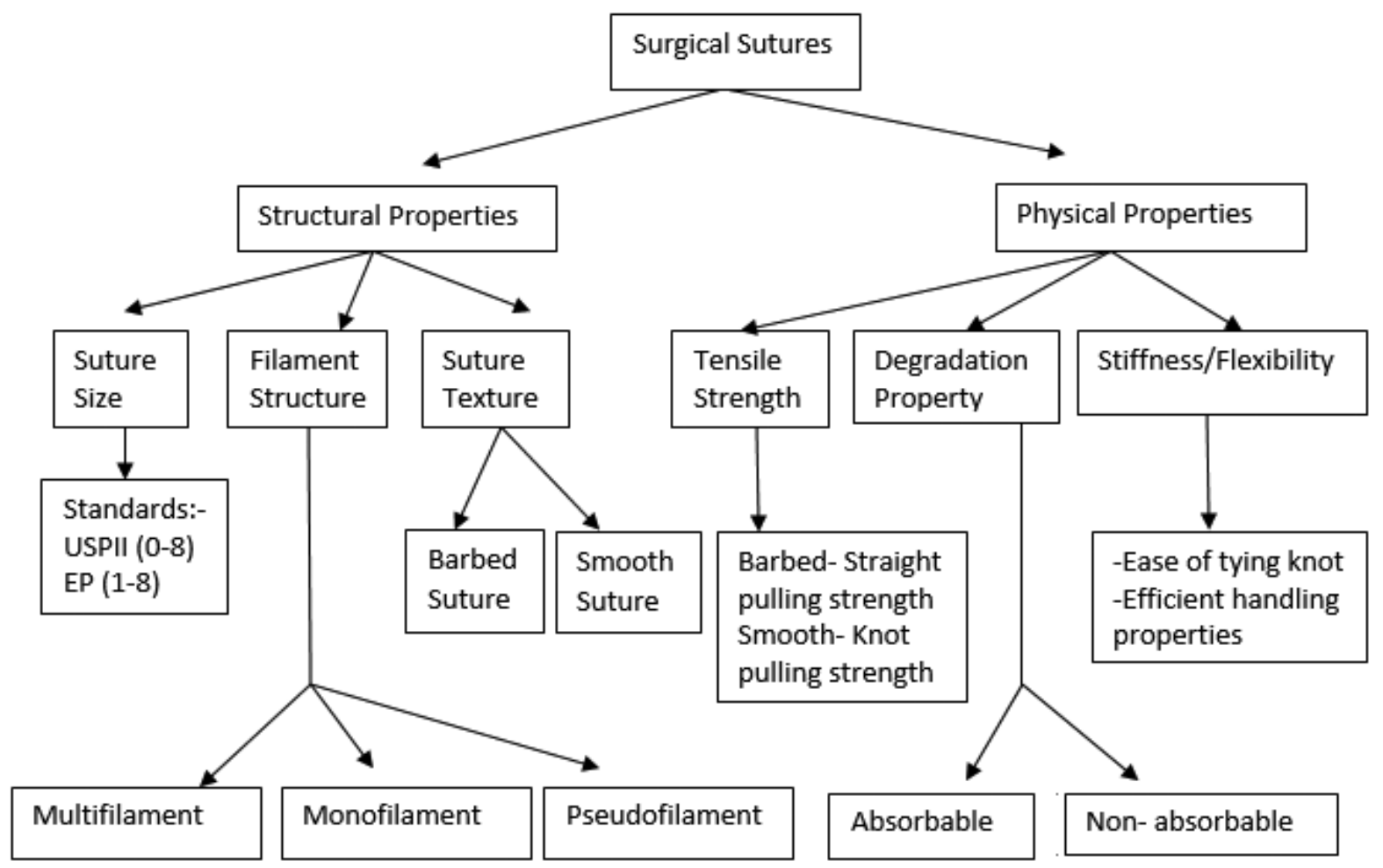

Figure 2. Classification of sutures on the basis of their physical and structural properties.

These polymeric biomaterials are conjugated with one or more than one bioactive agents in order to achieve controlled release kinetics. This in turn also improves the targeting efficiency. Polymeric biomaterials have ability to get fabricated with different ligands and groups. This modifies various physical and chemical properties of the polymers. This makes them more desirable candidates for their use in medical and pharmaceutical applications. These polymeric biomaterials can be engineered in such a way that these polymeric materials can act same as that of site specific drug delivery systems. Basically, the polymeric sutures can be described as two separate strands of materials which can be synthetic or natural which are intended in order to close of wounds. As per Acharya Sushruta an ancient Indian surgery, has explained the use of various surgical procedures, such as the use of horsehair, leather, and cotton as sutures for wound closure. Some cultures also used the ants and beetles as sutures for wound closing. However, the sutures prepared from catgut and silk are widely used for wound healing. With more and more researches, other than these natural polymers, researchers started using metal wires like gold wires for manufacturing of sutures.

The first catgut suture was synthesized in 1881 (Gariepy, 1994). However, these sutures which were made from the catgut or silk were have some drawbacks like they have some undesirable and unwanted tissue reactions and poor tensile strength of the polymeric threads. Hence, these polymeric natural polymers, such as catgut and tensile strength, should be removed and need to be replaced by some other polymeric materials which should have better tensile strength and no side effect (Pelz et al., 2015). So, in order to avoid these drawbacks of using natural polymers, these natural sutures were modified and later replaced by using the synthetic polymers which helped in creation of synthetic sutures. First, in 1970, most commonly used synthetic polymer for suture synthesis is poly glycolic acid. Later, PLGA polymer was also for manufacturing of synthetic sutures. These days, self-healing sutures have been widely used for wound healing. With time sutures have been modified which improved the healing process, immune response and tissue integrity. The delivery of antibiotics, anesthetics, anti-inflammatory agents, or analgesics from the suture can directly and efficiently delivers the drug into the wound area. These sutures are basically known as drug delivery suture and also called as drug eluting suture. The basic purpose of using sutures is to achieve the controlled release systems in order to create high drug concentrations at the wound area.

\section{History of drug eluting sutures}

In 2002, Food and Drug Administration (FDA) has approved triclosan-coated sutures for the first time. These triclosan-coated sutures have been reported to reduce wound infections during the treatment. These sutures were placed by using a surgical sterilized needle with which sutures were attached (Ming et al., 2007). The needle point is pointed toward the flesh and then pressed. A surgical knot is tied to the trailing thread which is usually a square knot. Basically, the main purpose of using sutures is to bring together the wound edges, which facilitate the faster wound healing. Use of drug-eluting suture can prevent wound infections to spread and give better healing (Rothenburger et al., 2002). The team's initial target was to use the sutures in order to prevent premature birth by bolstering the strength of a mother's cervix during initial stage of their third trimester. Despite closing cervix with a cerclage, devastating infections are known to occur 
from bacteria that migrate through the cervix and infect the fetus. Typically oral antimicrobials or vaginal pessaries are prescribed to prevent infection. However, the oral route may adversely affect healthy stomach bacteria, and both methods rely on patient compliance. By incorporating a localized drug delivery for the full 3-month duration needed to bring the fetus to term this new technology can usurp current treatments (Shibuya et al., 2004). Drug-eluting sutures can be developed using different techniques: (i) sutures coating by dip method and (ii) coating by grafting or electro-spinning. The effectiveness of drug-eluting sutures can be increased by the development of drug coated multifilament sutures having better transport properties, flexibility, and tensile strength and thereby manufacturing multidrug coated sutures having limited drug loading at desired site (Ming et al., 2008).

\section{Advantages of drug eluting sutures}

Various advantages of drug eluting sutures are as follows: (Greenberg et al., 2013; Parikh et al., 2009).

- Better wound healing and tissue regeneration.

- Amplified loading of drug and sustained drug delivery because of attached porosity characteristic of the sutures.

- Discharge of extracellular matrix proteins, cytokines, anti-microbial, anti-inflammatory, and pain management drugs to wound site.

- Mechanical properties of this unique suture do not compromise due to any amendment procedure.

\section{Drug Eluting Sutures as Drug Delivery Devices}

These days various novel sutures are developed with addition of some extra properties, such as addition of anti-microbial agents (Leaper et al., 2010; Rodeheaver et al., 1983), modification by addition of bio-active molecules, such as DNA (Labhasetwar et al., 1998), drugs (Loh, 1987), growth factors (Cummings et al., 2012), anti-bodies (Shibuya et al., 1999), silver (Blaker et al., 2004), and protein extra (Shibuya et al., 2003). This is done in order to customize and improve the wound healing properties of sutures.

The first anti-bacterial suture Vicryl Plus (which basically contains the polymer polyglactin which was coated with triclosan) was approved in 2002 by US-FDA. After this approval, the use of triclosan coating got increased and is used with various other suture materials in order to overcome bacterial adherence to the wound, and hence to prevent surgical infections (Ming et al., 2007). Sutures containing bio-active substance can also be used for different site specific procedures. These advances make the modified sutures as a better candidate to be used not only in re-generative medicine and invasive surgeries but also in tissue engineering (Lee et al., 2010).

Surgical sutures with drug eluting property can improve the post-operative complications like site infections. This property can be increased by selecting better therapeutic agent. This obviously reduces the need for supplemental anti-microbial drugs which usually have less potency at the site. Sustained release of drugs can also be achieved from drug eluting sutures. This property can allow better therapeutic concentration with prolonged duration without any toxic effects (Weldon et al., 2012). Drug-eluting sutures can be prepared by various methods like dip method, which is used in coating the sutures surface. They can also be developed by electro-spinning process. It will be the biggest achievement if we get the desired concentration and effect of the loaded drug in these sutures without affecting its mechanical properties. This can be achieved by enhancing/modifying the control release approaches (Viju and Thilagavathi, 2015).

Normal braided sutures can have bacterial adherence and this may increase the bacterial infections at the healing site because the bacteria can be trapped in braided filaments of the sutures. These braided sutures can be modified by coating with the various antibiotics for example tetracycline-coated silk suture (Chen et al., 2015). These tetracycline-coated silk sutures exhibit high anti-microbial property against Escherichia coli bacteria, and hence anti-microbial efficacy can be increased with appropriate drug concentration. In the same pattern, the braided silk sutures can also be coated with levofloxacin hydrochloride which showed similar result as that of tetracycline antibiotic with better susceptibility to E. coli. Suture to suture friction (caused by the friction between the suture threads) and stiffness caused by the blending of the fibers can be altered during anti-bacterial and anti-microbial treatment (Chen et al., 2015b).

The antibiotic levofloxacin can also be used in these sutures. Drug eluting sutures which contain levofloxacin loaded with the polymers poly (L-lactic acid) and poly-ethylene glycol are used for ophthalmic purpose. These sutures are made from bio-compatible polymers with hydrophilic nature. This property inhibits the bacterial growth (Staphylococcus epidermidis) (García-Vargas et al., 2014).

Casalini et al. discovered a theoretical model of sutured with polymer poly - e - caprolactone which is of bio-resorbable nature. The antibiotic used in these sutures is lidocaine. The study showed that the diffusion coefficient is increased and the half-life of the drug is also improved resulting in increased potency of the drug. The release studies of the lidocaine from suture showed better analgesic effects on tissue. The drug showed the release for nearly 75 hours on the anaesthetized tissues, and hence make the sutured as a better candidate for reducing the post-operative pain (Casalini et al., 2012).

Weldon et al. produced local anesthetic containing the drug bupivacaine which is eluted from the PLGA polymer. These sutures were prepared by electro-spinning process by changing the concentrations of anesthetic drug. The electro-spinned drug-eluting sutures showed better and desirable mechanical properties along with better drug diffusion on the wound tissues in rats. The drugrelease kinetic studies showed directly proportional relationship with increased concentration of the drug. These drug-eluting sutures were reported to have better post-operative analgesic effect for about 7-10 days with about 3 days of maximum degree analgesia. These local anesthetic containing sutures showed better effect without any adverse reactions (Weldon et al., 2012).

These days, a new novel design of core sheath architecture based yarns sutures has been discovered. These sutures were prepared from electrospinning process which can yield better mechanical strength and flexible fibers of sutures. This favors the incorporation of same or different bio-active molecules and dyes. These yarns can be further modified into the multifilament sutures for versatile use. An in vivo study of these yarns sutures have showed that inflammatory response and neointimal hyperplasia have been significantly reduced in porcine model. The results also 
showed the controlled release of bioactive drugs which give better prevention on neointimal hyperplasia. These results make these sutures as a better candidate for peripheral vascular and coronary artery bypass surgery (Zurita et al., 2006a).

Lee et al. (2013) successfully prepared surgical sutures with loaded with ibuprofen drug as pain-relief without compromising the mechanical strength of the sutures. The immobilization of the polymer polyethyleneamine coated with the active drug dexamethasone on absorbable sutures showed better controlled release of the active moiety for about 4 weeks without compromising the mechanical properties of the prepared suture's materials (polymer) (Morizumi et al., 2011). The benefits of the drug-eluting sutures can be further increased by using the drug combinations. Multiple-drugs in combination can exhibit either synergistic effects or additive effects on the affected site.

Some complications, such as severe scar formation, delayed wound healing, and skin irritations, can occur by using the sutures, and hence further studies are required in order to get more stable and more beneficial sutures (Chen et al., 2012; Colombo et al., 2005; Shukla et al., 2011). Various clinical studies and modifications in the bioactive materials can enhance the functionality of the sutures and reduce these types of adverse effects.

\section{Clinical Applications of Drug Eluting Sutures}

Some of drug eluting sutures with their clinical applications are enlisted in Table 1 (Dennis et al., 2016).

\section{Methods of Manufacturing of Sutures}

The drug can inculcated during synthesis of sutures or it can be incorporated into already manufactured sutures (Champeau et al., 2017). Various methods are described below and shown in Figure 3 as a flowchart. The advantages and disadvantages of various methods have been summarized in Table 2 (Dennis et al., 2016).

\section{Methods inculcating active pharmaceutical ingredient (API)}

The main manufacturing processes for transformation of raw polymer into suture threads are based on melt or wet spinning processes. The polymer is melted or solubilized into an adequate solvent, and the liquid is extruded through a spinneret. The same processes have been used to create drug-eluting sutures by simply mixing the drug with the polymer material before spinning in one step. In most cases, the drug and the polymer are solubilized together in an organic solvent and then spun by gravity or under the pressure of a syringe. Then, either the fiber is dried or precipitated into a dedicated medium (Perale et al., 2010). During the last years, electrospinning that uses an electrical field to draw fibers from the liquid has become an emerging technique to produce very thin (micro or Nano) fibers and a variety of electrospinning processes now exists. Because of the easiness of these processes and their low cost, they have been widely studied to form drug-eluting sutures. Moreover, these processes enable to operate continuously and to limit the processing steps, making the low

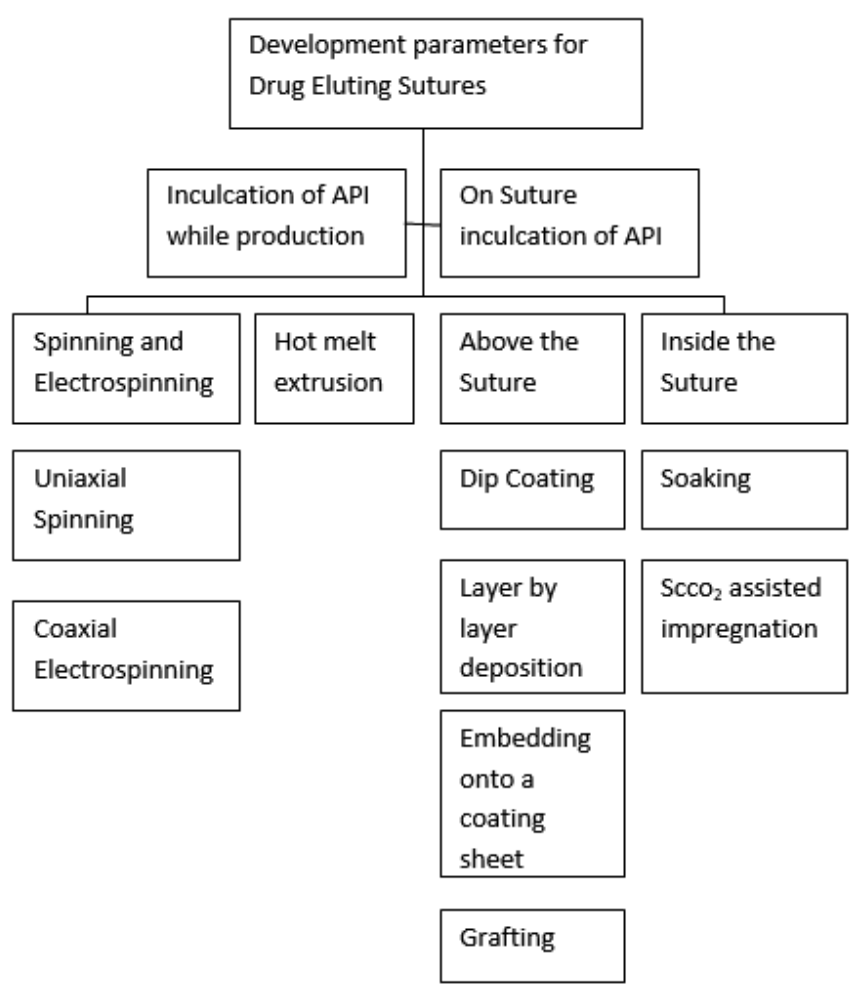

Figure 3. Methods for production of sutures.

Table 1. Various suture materials and their clinical applications.

\begin{tabular}{|c|c|c|}
\hline Suture material & Bioactives modifiers & Clinical application \\
\hline Silk & Tetracycline as anti-bacterial agent & $\begin{array}{l}\text { Antimicrobial activity as well as the zone of inhibition was better for } E \text {. Coli bacteria as } \\
\text { compared to the } S \text {. aureus. }\end{array}$ \\
\hline Braided silk & Levofloxacin as anti-bacterial agent & $\begin{array}{l}\text { Antimicrobial activity was seen to last for about } 7 \text { days. The zone of inhibition and } \\
\text { antimicrobial property was better for } E \text {. Coli bacteria as compared to the } S \text {. aureus. }\end{array}$ \\
\hline Polypropylene & Vancomycin Hydrochloride & $\begin{array}{l}\text { The release studies of the lidocaine from suture showed better analgesic effects on tissue. The } \\
\text { drug showed the release for nearly } 75 \text { hours on the anaesthetized tissues }\end{array}$ \\
\hline PLGA & Bupivacaine as Local Anaesthetic agent & $\begin{array}{l}\text { Better post-operative analgesic effect for about } 7-10 \text { days with about } 3 \text { days of maximum } \\
\text { degree analgesia }\end{array}$ \\
\hline \multirow[t]{2}{*}{ Polyvinylidene difluoride and PLGA } & \multirow{2}{*}{$\begin{array}{l}\text { Tacrolimus as immunosuppressive agent and } \\
\text { ibuprofen as NSAIDS }\end{array}$} & The results showed prevention the neo-intimal hyperplasia. \\
\hline & & $\begin{array}{l}\text { The polymer PLGA used give better relief from post-operative pain about } 6 \text { days of drug } \\
\text { release. }\end{array}$ \\
\hline PLGA and Poly (e-caprolactone) & $\begin{array}{l}\text { Dexamethasone as anti-inflammatory agent } \\
\text { and Diclofenac1 Hydrotalcite }\end{array}$ & $\begin{array}{l}\text { The release rate of the selected composition against the inflammation (in-vivo) showed better } \\
\text { tensile strength and can be used in post-operative pain. }\end{array}$ \\
\hline
\end{tabular}


Table 2. Various methods with their advantages and disadvantages.

\begin{tabular}{|c|c|c|}
\hline Manufacturing processes & Benefits & Drawbacks \\
\hline $\begin{array}{l}\text { Electrospinning } \\
\text { (uniaxial and coaxial) }\end{array}$ & $\begin{array}{l}\text { Equipment is same as that used for raw sutures engineering } \\
\text { Less temperatures (processing of thermolabile drugs could be done) } \\
\text { Different architectures and consequent drug release profiles can be produced } \\
\text { by modifying the equipment configuration (uniaxial/coaxial) } \\
\text { Control of the diameter of the suture by adjusting the process conditions and } \\
\text { the equipment } \\
\text { One-step process }\end{array}$ & $\begin{array}{l}\text { Organic solvents which are toxic should be removed } \\
\text { Uniaxial: API close to the surface and consequent burst release } \\
\text { Uniaxial: mechanical properties decrease with increasing the drug content } \\
\text { Coaxial: collapse after release and loss of mechanical properties } \\
\text { Organic solvent and electrical field can be deleterious for labile APIs }\end{array}$ \\
\hline Melt extrusion & $\begin{array}{l}\text { Easy to implement } \\
\text { Solvent free } \\
\text { Homogeneous distribution of the API along the cross section } \\
\text { One-step process }\end{array}$ & $\begin{array}{l}\text { Thermolabile drugs cannot be processed with high melting temperature } \\
\text { polymers } \\
\text { Mechanical properties decrease with increasing the drug content }\end{array}$ \\
\hline Coating & $\begin{array}{l}\text { Dip-coating and layer-by-layer: easy to implement } \\
\text { Tunable release profile by varying the properties of the coating: architecture } \\
\text { or properties of the polymer } \\
\text { Possibility to improve or maintain the tensile properties of the suture even at } \\
\text { high drug content by forming a coating that can carry the load or not }\end{array}$ & $\begin{array}{l}\text { Organic solvents used for the formation of the coating must be removed } \\
\text { The possible original coating of commercial sutures must be removed for } \\
\text { a good adherence of the coating }\end{array}$ \\
\hline Grafting & $\begin{array}{l}\text { Tunable release profile by varying the drug/grafted polymer interactions and } \\
\text { the grafting properties } \\
\text { Good control of the coating thickness } \\
\text { Control of the chemical composition of the surface with the grafting } \\
\text { conditions } \\
\text { The surface can be designed to be stimuli-responsive }\end{array}$ & $\begin{array}{l}\text { Poor control of the thickness of the coating } \\
\text { Residual monomers and organic solvents used for the formation of the } \\
\text { coating must be removed } \\
\text { Monomers can penetrate into the bulk of the suture and decrease the } \\
\text { mechanical properties }\end{array}$ \\
\hline Soaking & $\begin{array}{l}\text { Easy to implement } \\
\text { Low temperature processing } \\
\text { Possible sustained drug release }\end{array}$ & $\begin{array}{l}\text { Slow process } \\
\text { Organic solvents used for the drug loading must be removed }\end{array}$ \\
\hline $\begin{array}{l}\text { Supercritical } \mathrm{CO}_{2} \text { - assisted } \\
\text { impregnation }\end{array}$ & $\begin{array}{l}\text { Do not use organic solvent } \\
\text { Drug loading controlled by varying the operational conditions } \\
\text { Low temperature processing } \\
\text { Possible sustained drug release }\end{array}$ & $\begin{array}{l}\text { Mechanical properties impacted } \\
\text { Mechanical properties impacted by the } \mathrm{scCO}_{2} \text { treatment and the drug } \\
\text { (modification of the microstructure) } \\
\text { Specific equipment required } \\
\text { Not applicable to high molar mass APIs }\end{array}$ \\
\hline
\end{tabular}

cost manufacturing of drug-eluting sutures with these processes a viable proposition (Nagy et al., 2013; Scaffaro et al., 2013).

\section{Electrospinning}

The electrospinning has attracted a growing attention in better drug delivery (Fig. 4) and tissue engineering and relevant reviews have been recently published on drug delivery electrospun fibers (Chou et al., 2015; Zamani et al., 2013) and the effect of processing variables on their manufacturing. The drug/polymer solution is loaded in a syringe and passed through capillary. A high voltage is applied in the capillary. The charged jet is formed that triggers the fast evaporation of the solvent and the elongation of the fiber that is formed and deposited on the collector. The drug-loaded fibers are generally recovered on the collector as nonwoven mats (Weldon et al., 2012). By using a rotating collector, monofilament or multifilament of drug-loaded sutures can be produced from various polymers and braided drug loaded microfibers are prepared by combining the procedure of electrospinning process along with the braiding equipment. Moreover, through an adequate selection of polymers or polymer blends, the properties of the final device can be tuned, such as the mechanical properties and the degradation rate. The drug release kinetics can be controlled not only by the nature of the polymer matrix but also by the drug loading and by the diameter of the suture (Hu et al., 2010). Since this process works at low temperature, it allows to process thermo labile APIs, such as genes, peptides growth factors, and DNA. A large variety of API-polymer systems has been produced by varying both the nature of the API and the polymer and several APIs can be loaded in the same fiber for multipurpose action (Blakney et al., 2014).
Electrospun fibers containing small hydrophobic molecules and large biological molecules can exhibit a release profile for more than 1 week due to their low solubility in biological fluids and to their preferential partitioning into hydrophobic polymers, whereas prolonged release profiles from small hydrophilic molecules-containing fibers are more complicated to obtain (Chou et al., 2015). Independently of the physicochemical properties of the API, it impacts the properties of the electrospun fibers. For example, the drug can modify the electrical conductivity or the viscosity of the electrospun solution that consequently affects the diameter of the fiber. Moreover, an increase of the drug loading leads to a decrease of the tensile power of the prepared sutures. Consequently, the process parameters must be optimized for each API-polymer system, such as the solution properties (viscosity and conductivity), the ambient conditions (humidity and temperature), and the processing parameters (spinneret diameter, flow rate, and field strength) (Meinel et al., 2012). Drug contents up to $22 \mathrm{wt} \%$ (by weight of polymer) have been reported, but high drug contents exert a deleterious effect on the tensile strength. For example, a drug content of $22 \mathrm{wt} \%$ of bupivacaine $\mathrm{HCl}$ in PLGA resulted in a $70 \%$ decrease of the tensile strength compared with the suture that did not contain drug (Weldon et al., 2012).

In uniaxial electrospinning, the API can concentrate close to the surface of the fiber due to drug migration during the rapid solvent evaporation. This phenomenon specially occurs with small hydrophilic molecules that present a low compatibility with nonpolar matrix and is more critical for thinner manufacturing processes. Advantages and drawbacks of the process can be - i) compatibility of APIs with the process, ii) drug release profile, iii) mechanical properties and diameter of the suture, iv) soaking 


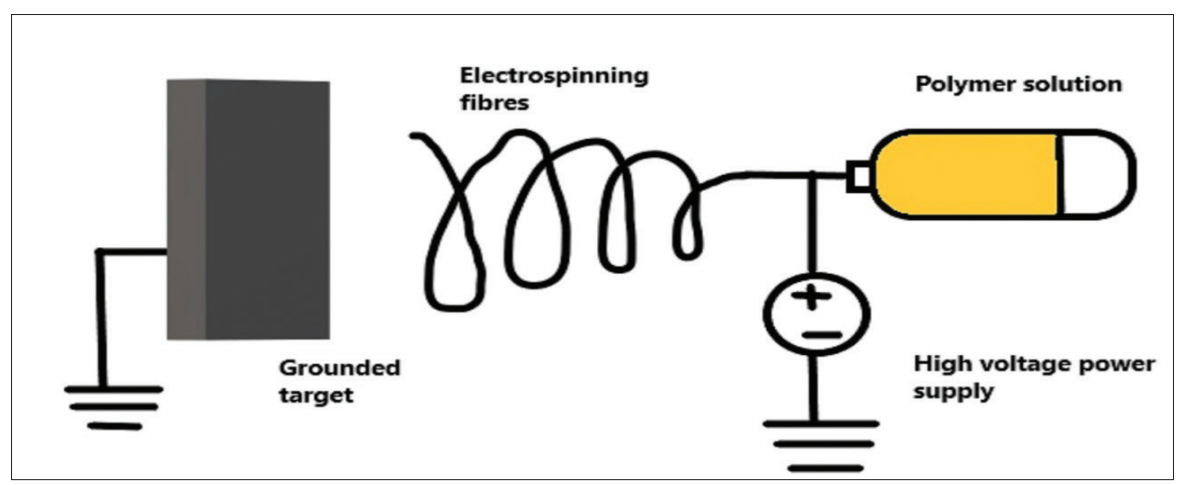

Figure 4. Electrospinning technique.

low cost impregnation of already manufactured sutures, v) longer duration, vi) organic solvent residues must be removed, vii) low temperature, viii) not too large to be able to diffuse into the polymer, ix) soluble in a good swelling solvent of the polymer (He et al., 2009; Kenawy et al., 2002).

The electrospinning apparatus has been modified into various configurations in order to obtain different API-polymer distributions into the fibre. For example, coaxial electrospinning allows for the formation of a composite fibre with core-shell architecture, the API being encapsulated inside the core of the fibre surrounded by a shell of polymer (He et al., 2009). In this process, the API and the polymer are loaded into two separated syringes, the polymer passes into a capillary and the drug solution is injected into the centre of this capillary. By adjusting the respective flow rates of the polymer and API solutions, the core-shell thicknesses can be tuned. This technique is particularly interesting when, the API and the polymer are Immiscible or when the API is sensitive to organic solvents or electric discharges (such as growth factors and proteins). However, the drug release of such system is slower due to the diffusion of the drug from the core through the polymer shell, and the architecture of the fibres tend to collapse once the drug is eluted, thus impacting the tensile properties (Kenawy et al., 2002).

As already mentioned, uniaxial and coaxial electrospinning technique often require to dissolve the polymer and the drug in organic solvents. To respect the FDA requirements the final suture must be dried to remove the residual solvent and this drying step can be time and energy-consuming ( $\mathrm{He}$ et al., 2009).

\section{Melt extrusion}

Melt processing is a way to solve the problem of solvent removal because the polymer is melted instead of being solubilized in solvent. It enables to produce reproducible materials and the drug is homogeneously distributed within the cross section of the suture. In order to slow down the drug release rate, the drug can also be modified before being mixed and processed with the polymer (Perale et al., 2010). For example, diclofenac was intercalated into a synthetic hydrotalcite and mixed with poly ( $\varepsilon$-caprolactone) (PCL) before extrusion of the mixture. The intercalated drug was completely released from PCL suture after 55 days, whereas the raw drug embedded in PCL was totally released after 14 days, the two sutures containing similar amounts of drug (Catanzano et al., 2014). However, few studies have been reported about the manufacturing of drug eluting sutures by melt extrusion that may be explained by the processing temperature (Blakney et al., 2014). Indeed, this process cannot be applied to thermolabile APIs with polymers that exhibit a high melting temperature.

The threads obtained by melt extrusion have a diameter ranging from 50 to $300 \mu \mathrm{m}$, whereas the diameters of electrospun fibers range from nanometers to $350 \mu \mathrm{m}$. Consequently, the multifilament sutures result from the woven of electrospun monofilaments.

\section{Post inculcation of API to a previously prepared suture}

In this case, there is no need to manufacture whole API or any polymer device, the required drug can be post inculcated to a previously prepared suture. Generally, the raw suture is prepared by electrospinning or melts extrusion without adding API. The two major approaches for this are addition of drug on or inside the prepared suture (Dennis et al., 2016).

\section{On suture inculcation of API}

Coating: The easiest manner for after addition of API to the suture is by adsorbing the drug on to suture surface even in the case where emergent release is expected after the surgery. In this technique, a non-bio absorbable polymer is loaded with the API (Bölgen et al., 2007). For controlling the release, a coating containing mixture if both drug and polymer can be done on the surface of the suture. The drug release can then be modified by varying coating material and its concentrations. Various properties, such as porosity, degradation rate, thickness, and chemical nature, can be changed with modifications in coating materials. For example, ETHICON Inc. has already commercialized three drug-delivery sutures in which triclosan, a broad-spectrum antimicrobial agent, is embedded into a coating of PLGA: the MONOCRYLTM Plus, the PDSTM Plus, and the coated VICRYL ${ }^{\mathrm{TM}}$ Plus which are three absorbable sutures made of a copolymer of glycolide and $\varepsilon$-caprolactone, poly(p-dioxanone) and poly(glycolic-co-lactic) acid, respectively. An immediate release enables to kill the bacteria during the first 2 days, which is the time necessary for the epidermis to heal which then limits the bacteria entrance in the body. The ability of these sutures to inhibit proliferation during 11 days has also been demonstrated The composition and the manufacturing process of the coating are 
confidential, but the efficiency of such a coating has been clinically demonstrated (Thimour-Bergström et al., 2013).

The layer-by-layer deposition of polyelectrolytes is a coating technology applicable to sutures that exhibit a charged surface. A well-controlled architecture is obtained by alternatively depositing oppositely charged polymers, the drug being simultaneously loaded or post-impregnated into the grown multilayer. For instance, a commercial silk fiber has been coated with sequential layers of poly (allylamine hydrochloride) and dextran and hyaloplasm acid. The coated suture was then soaked into an aqueous solution of ibuprofen to obtain the final device. After 24 hours, $76 \%$ of the loaded ibuprofen was released (Wang et al., 2009).

Whereas the layer-by-layer deposition technique requires several layer-deposition steps, other coating techniques are faster. The suture can be dip-coated in a solution containing the drug. The solution is either a polymer solution, an emulsion containing the drug which can bind to the polymeric solution (Lee et al., 2014).

In 1996, a patented method based on the dip-coating of surgical implants or dressing materials, proposed to first coat a water-insoluble drug in micro particulate or microcrystalline solid form with a lipidic membrane to ensure the suspension of these microparticles in water. Then, the implant was dip-coated into this suspension. The lipidic membrane aims at improving the adherence of the microparticles to the implant, to protect the drug from oxidation or from possible reaction with the implant surface and to control the rate of drug release. The authors claimed that up to $4 \mathrm{~g}$ of the drug can be loaded per gram of implant (Champeau et al., 2017). Elsner et al. dipped a Maxon ${ }^{\mathrm{TM}}$ polyglyconate suture into an organic/water emulsion, the water containing an antibiotic drug, and the organic phase containing poly (D, L lactic-co-glycolic) acid stabilized with surfactant. Controlling the P (D, L) LGA molecular weight, the organic/aqueous phase ratio and the polymer content allow for modifying the shell microstructure (e.g., thickness of pore walls and connectivity) and thus, the diffusion of the drug. By reducing the pore size by $70 \%$, a reduction of the burst release by $30 \%$ and a prolonged drug release up to $40-50$ days were achieved. Similarly, when the coating is formed from a polymer solution, the drug content and the release profile can be tuned by varying the polymer (or copolymer) composition. Indeed, selecting a polymer that possesses a good affinity for the drug (e.g., electrostatic interactions, hydrogen bonds, and similar solubility parameters) will favor the dissolution of the drug in the polymer solution and its further embedment in the coating. The drug release may depend on the degradation or not of the polymer matrix, on the easiness of the diffusion of the drug through the matrix and on the partition of the drug between the biological fluids and the polymer. A good affinity for the polymer can favor a slow release (Elsner et al., 2009).

For instance, Zurita et al. optimized the composition of the coating made of a co-polymer based on $\varepsilon$-caprolactone, lactide, and trimethylene carbonate (Polylactide/Polytrimethylenecarbonate) to embed triclosan around a multifilament suture. Creating a polymer with a good miscibility with the drug enabled the authors to obtain high drug content and a homogeneous coating. Suture materials and, especially, braided sutures are susceptible for surgical site infections due to bacterial bioadhesion and to the colonization and proliferation of bacteria between the braided filaments (Zurita et al., 2006b).
Recently, Chen et al. compared two techniques to create an antibacterial braided silk suture using a coating made of levofloxacin hydrochloride and PCL. The coating was applied by a two-dipping-two-rolling coating machine in order to control the thickness of the coating. In case 1, the silk strands were individually coated before being braided. In case 2 , the strands were first braided and the resulting braided suture was then coated, the twodipping two-rolling techniques allowing for a good penetration of the coating into the inner space of the suture. Both sutures released the drug during 5-6 days and exhibited same anti-bacterial activity against both Gram-negative and Gram-positive bacteria. The authors performed an intensive characterization of the handling properties and physical properties of these sutures, which are critical criteria for the clinical use of sutures. They showed that the properties of the coated-braided suture tended to be similar to those of monofilament sutures, i.e., the bending stiffness increased, whereas the thread-to-thread friction decreased due to the penetration of the coating between the strands. The coating of each strand before braiding leads to slight changes in the properties. It was investigated that how the number of coating repetition of each braid impacts the handling properties and physical properties of the braided suture. Increasing the number of coating repetitions led to increase the suture diameter and to decrease the knot-pull tensile strength and the bending stiffness. The PCL coating tended to act as a protection against hairiness, but the suture-to-suture friction tests resulted in the formation of clusters of the coating material. The commercialized sutures are often covered by a coating containing either a dye to make it more visible for the surgeon or with a lubricant to facilitate their implantation. The previous coating processes require removing this pre-existing coating in order to ensure a good adherence to the fiber (Chen et al., 2015b).

Lee et al. proposed an original technique based on the physical assembly of a commercialized suture and a sheet containing the drug that was braided manually around the suture. The prepared sheet of PLGA loaded with ibuprofen was prepared with various drug concentrations and with a multilayer structure to tailor the release. The objective of the authors was to increase the drug content as necessary while maintaining the same mechanical properties as the original suture. The mechanical strength of the suture was improved by the presence of the sheet, the ultimate tensile strength being increased by more than $30 \%$ compared with the original suture. Obviously, upscaling of this technique is not feasible considering the difficulty to wrap the suture with strand of sheet minimizing gap and overlap between the strands. Similarly, an API-containing fibrous sheath can be created around a suture by using processes, such as electrospinning, to produce the coating that is deposited around the pre manufactured suture (Lee et al., 2013).

Globally, the presence of a coating consistently increases the diameter of the suture and alters its tensile strength calculated from the total diameter of the final fiber. Nevertheless, coatings with poor mechanical resistance made of porous polymer or particles do not impact the tensile power of the sutures itself. On the other side, the mechanical power of the suture can be improved by forming a load-bearing coating (Zhukovskii et al., 2007).

\section{Superficial attachment on suture}

The coating techniques described earlier suffer from a poor control of the thickness of the coating. These problems can 
be overcome by directly functionalizing the surface of the fiber. The radiation grafting method has been widely used since the thickness of the grafted layer, its composition, and morphology can be controlled by tuning the reaction conditions (irradiation dose, monomers concentration, proportion of monomers in case of copolymer grafting, temperature, and reaction time). The polymer suture is first irradiated and then a monomer is grafted to the suture and transformed to form chemical groups able to interact reversibly with a specific drug. Various monomers have been grafted to different sutures (Singh and Tyagi, 1989). Polymergrafted polypropylene (PP), polycaproamide, or silk sutures were able to form covalent or ionic interactions with antimicrobial or anti-inflammatory drugs. Moreover, the drug release profile of the grafted coating can be controlled by grafting different monomers and by forming stimuli-responsive network (Modak et al., 1998).

However, $\gamma$-irradiation induces a reorganization of the crystallinity of PP which results in a significant drop of more than $50 \%$ of the tensile strength and of $70 \%$ of the elongation at break. The grafting has also been observed into the bulk of PP sutures which also alters the crystallinity and depending on the grafting level, can either improve the mechanical properties by reinforcing the suture or decreases them by pushing apart the polymer chains. Instead of grafting monomers to the suture, Wu et al. grafted triclosan loaded nanogels on commercial multifilament braided silk sutures after activation of the carboxyl groups of silk. It resulted in negligible changes in the tensile strength and in the diameter. The antibacterial activity tests have evidenced a longer-term efficiency of the modified suture against Staphylococcus aureus and E. coli bacteria compared to the commercial VICRYL Plus suture (Wu et al., 2016).

\section{API laden inside the suture}

Other than coating, the permeation of API inside the suture can also be done. With the process of permeation, API is dispersed into the bulk of the suture while preserving the initial suture configuration. The drug loading is performed in batch process.

Soaking: The simplest method to load the API is to soak the polymer into a concentrated API solution, let the API diffuses into the matrix and be retained in the matrix by favorable interactions, and finally evaporate the solvent. The choice of the solvent is thus acute; it must be a good solvent for the API and be able to swell the polymer matrix in order to facilitate the diffusion of the API but without dissolving the suture. The yield of API loading is influenced by the drug concentration in the solution, the soaking time, and the API/polymer interactions. Poly (p-dioxanone) (PDSII1) from Ethicon has been soaked in dichloromethane solutions of various ibuprofen concentrations (2-10 wt $\%$ ) during 0-24 hours. A large amount of the loaded drug was deposited on the surface. After removal of this deposited drug, the yield of impregnation varied from $0.025 \%$ to $0.27 \%$ (gibuprofen/gsuture). The knot tensile parameters were decreased up to $23 \%$ for the breaking strain and $15 \%$ for the Young's modulus. The release duration depended on the amount of loaded drug. However, the use of dichloromethane requires the drying of the final suture in air during 24 hours and for 6 hours under vacuum in order to reach the FDA requirements $(<600 \mathrm{ppm}$ for dichloromethane). The same study has been performed by the same authors on poly (pdioxanone) loaded with triclosan and drug loading up to $2.90 \%$ (gtriclosan/gsuture) was achieved. This procedure was compared to the coating of the suture obtained by dipping the suture into a solution of polycaprolactone and triclosan. The same drug concentration was used in the bath of both techniques. The authors highlighted that the soaking process takes more time than the coating technique to load a similar amount of triclosan: 24 hours versus 30 seconds. However, the release was more sustained in case of soaking: $95 \%$ of the drug was released after 200 hours compared to 110 hours for the coated suture. Finally, the soaking technique presents several drawbacks: it requires long time processing due to the slow diffusion of the drug into the polymer matrix, the yield of drug loading is low, the mechanical properties of the suture can be impacted by the use of the solvent (swelling and induced crystallization), and it is difficult to remove the residual solvent (Blanco et al., 2009).

Supercritical $\mathrm{CO}_{2}$-assisted impregnation: To tackle the problem entailed by organic solvents, a new technology based on the use of supercritical $\mathrm{CO}_{2}\left(\mathrm{ScCO}_{2}\right)$ has been developed (Fig. 5) and has sparked a growing research interest. The principle is similar to the soaking method, but the organic solvent is replaced by $\mathrm{ScCO}_{2}$ (supercritical state above $31^{\circ} \mathrm{C}$ and 73.8 bar). $\mathrm{ScCO}_{2}$ can absorb in most of the conventional polymers and swell them. Moreover, $\mathrm{ScCO}_{2}$ can solubilize many low-molecular weight and non-polar APIs and carry them into the polymer matrices. This process has several advantages since $\mathrm{CO}_{2}$ is inexpensive, environment friendly, it has low critical coordinates which allows to process with thermolabile APIs, and it enables to recover a final impregnated suture free of any solvent residue just by depressurization after impregnation. Due to the use of high pressure, specific high-pressure reactors and pressurization/ depressurization systems are required and the investment cost of a production plant is higher than for the other processes. Preformed multifilament and monofilament sutures made of bioabsorbable and nonabsorbable semicrystalline polymers, such as PLGA, poly(L-lactic acid) (PLLA), polyethylene terephthalate, and PP were impregnated. The time necessary to reach the maximal drug loading is low (about 1 hour) since the diameter of these devices is lower than $300 \mu \mathrm{m}$. The amount of drug loaded in the polymer can be simply tuned by varying the operating conditions, such as the pressure, the temperature, the contact time, and the depressurization conditions. The $\mathrm{ScCO}_{2}$-assisted impregnation process was found to be adapted for polymer having good chain mobility and good interaction with the drug. For example, ketoprofen having a better affinity for PLLA compared with aspirin, the maximal drug loading achieved with ketoprofen was $32.5 \%$, whereas it reached only $8.1 \%$ with aspirin. The impregnation process tends to impact the tensile properties of the sutures (tensile strength, tensile modulus, and breaking strength), especially when increasing the processing temperature close to the melting temperature of the polymer (e.g., between $70^{\circ} \mathrm{C}$ and $100^{\circ} \mathrm{C}$ for PLLA) due to the modification of the microstructure (Champeau et al., 2015).

Sugiura et al. (2005) have shown that tranilast, a hydrophobic drug, can be progressively released from a PLA suture of $200 \mu \mathrm{m}$ of diameter beyond 2 months. For the first time, Geiger et al. have performed a dual-drug impregnation of a core-shell fiber. The $\mathrm{ScCO}_{2}$-assisted impregnation of a PCL fiber coated with a PCL-gelatin shell led to the loading of the model hydrophobic 
drug into the hydrophobic PCL core and to the hydrophilic drug into the hydrophilic shell. Interestingly, $\mathrm{ScCO}_{2}$-impregnated fiber presented a controlled bimodal release and the release was slower compared to a fiber soaked in a solution containing the two drugs (Geiger et al., 2015).

\section{Patent Literature on Drug Eluting Sutures}

A number of patents have been published related to antimicrobial absorbable sutures, fluid emitting suture needles, and other devices pertaining to drug delivery. Table 3 enlists the data on patent related to drug eluting sutures.
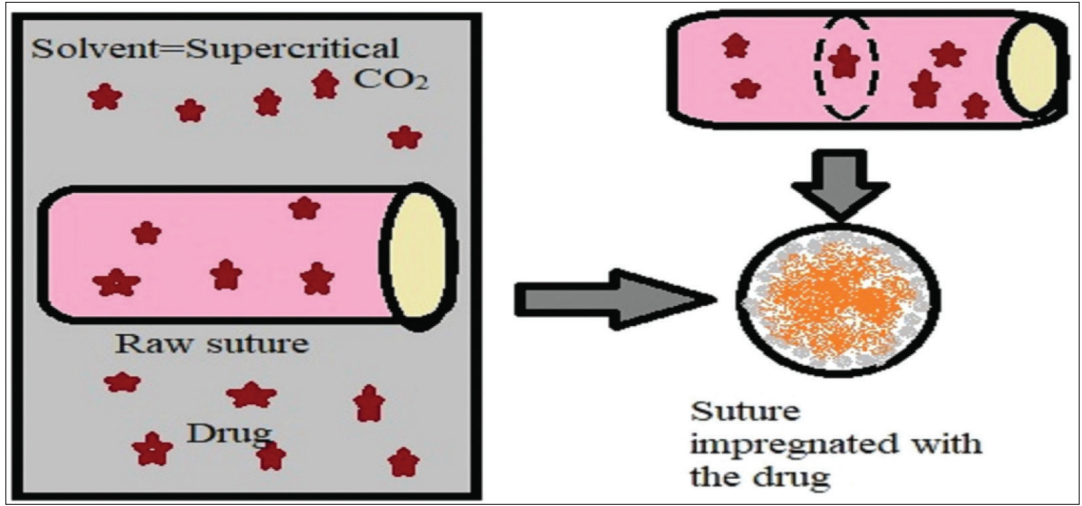

Figure 5. Supercritical $\mathrm{CO}_{2}$ assisted impregnation of drug.

Table 3. Patent literature on drug eluting sutures.

\begin{tabular}{|c|c|c|c|c|}
\hline S. no & Patent no & Patent title & Description & Reference \\
\hline 1 & $\begin{array}{l}\text { US } \\
2004 / 0039441 \\
\text { A1 }\end{array}$ & $\begin{array}{l}\text { Drug eluting implantable } \\
\text { medical device }\end{array}$ & $\begin{array}{l}\text { The medical devices, such as synthetic grafts, stents extra contains coating material which is used } \\
\text { for controlled release. The polymer Poly(DL-Lactide-co-Glycolide) selected is bio-absorbable, } \\
\text { bio-compatible, bio-erodible, bio-degradable, non-toxic and at least one of the pharmaceutical } \\
\text { active substance or any bio-active agent can be incorporated in the matrix. When drug eluting } \\
\text { medical device is implanted into patient, it delivers the drugs in a controlled and desired } \\
\text { rate which depend on the drug's physical and chemical properties as well as on the site of } \\
\text { implantation. }\end{array}$ & Rowland et al. (2004) \\
\hline 2 & $\begin{array}{l}\text { US } \\
2004 / 0171323 \\
\text { A1 }\end{array}$ & $\begin{array}{l}\text { Antimicrobial, synthetic, } \\
\text { fibrous, And tubular medical } \\
\text { devices }\end{array}$ & $\begin{array}{l}\text { The present invention is directed toward antimicrobial absorbable and non-absorbable fibrous } \\
\text { and tubular medical devices comprising Synthetic polymers and one or more antimicrobial agent } \\
\text { molecularly dispersed within the Surface to allow the continuous release of Said agent or agents } \\
\text { under Simulated physiologic conditions for at least } 1 \text { week. }\end{array}$ & Shalaby (2004) \\
\hline 3 & $\begin{array}{l}\text { US } \\
2004 / 0185250 \\
\text { A1 }\end{array}$ & $\begin{array}{l}\text { Triclosan containing } \\
\text { absorbable sutures with } \\
\text { extended anti-microbial } \\
\text { properties }\end{array}$ & $\begin{array}{l}\text { Absorbable anti-microbial sutures containing Triclosan with extended anti-microbial properties } \\
\text { were prepared. Triclosan was incorporated in the absorbable sutures by processes like coating and } \\
\text { soaking. The processes like soaking and coating of the active ingredient triclosan solutions before } \\
\text { they are further processed in to different sized fibers. }\end{array}$ & John (2004) \\
\hline 4 & $\begin{array}{c}\text { US } \\
2004 / 0193257 \\
\text { A1 }\end{array}$ & $\begin{array}{l}\text { Medical devices with drug } \\
\text { eluting properties }\end{array}$ & $\begin{array}{l}\text { A medical device comprises a shape memory alloy having a Reverse martensitic transformation } \\
\text { start temperature of Greater than or equal to about } 0^{\circ} \mathrm{C} \text {; and a drug coating Comprising a } \\
\text { polymeric resin and a biologically active Agent. A method of manufacturing a stent comprises } \\
\text { cold Forming a shape memory alloy from a Wire; heat treating the Cold formed shape memory } \\
\text { alloy at a temperatures greater Than that at Which a martensitic transformation can occur; And } \\
\text { coating the stent With a drug coating comprising a Biologically active agent. }\end{array}$ & Wu et al. (2004) \\
\hline 5 & $\begin{array}{c}\text { US } \\
2005 / 0070959 \\
\text { A1 }\end{array}$ & Fluid emitting suture needle & $\begin{array}{l}\text { This experiment gives suture needle which are multifunctional that can be used to draw a Suture } \\
\text { through tissues. The suture needle possesses an internal cavity which is capable of containing the } \\
\text { fluid. This fluid containing the active ingredient may be flowed through needle tip by compressed } \\
\text { gas which is sealed in a small cavity which is adjacent to that fluid. The rate at which this fluid } \\
\text { is flowed through the suture needle can be controlled by adjusting the viscosity of the fluid, by } \\
\text { modifying the design of the needle suture. }\end{array}$ & Cichocki (2005) \\
\hline 6 & $\begin{array}{l}\text { US } \\
2007 / 0010856 \mathrm{~A} 1\end{array}$ & $\begin{array}{l}\text { Antimicrobial sutures and } \\
\text { methods of making them }\end{array}$ & $\begin{array}{l}\text { Multifilament sutures are prepared by permeating the suture with an antimicrobial solution and } \\
\text { applying an antimicrobial coating to the suture. }\end{array}$ & Cohen (2007) \\
\hline 7 & $\begin{array}{c}\text { US } \\
2009 / 0155326 \\
\text { A1 }\end{array}$ & $\begin{array}{l}\text { Layered drug delivery } \\
\text { polymer Monoflament fibers }\end{array}$ & $\begin{array}{l}\text { This invention is a type of layered polymeric mono-filament fibers containing active ingredient } \\
\text { delivery device. In these drug delivery devices, each layer of the polymeric monofilaments can } \\
\text { contain different type of polymers or polymer combinations, different type of drugs and their } \\
\text { combinations in order to achieve synergistic properties. This layered nature of sutures increases } \\
\text { the capability to increase the release of one or more type of drugs and their combinations as per } \\
\text { the need. }\end{array}$ & Mack et al. (2009) \\
\hline 8 & $\begin{array}{l}\text { US } \\
20130317545 \mathrm{~A} 1\end{array}$ & $\begin{array}{l}\text { Drug-eluting self-retaining } \\
\text { Sutures and methods relating } \\
\text { Thereto }\end{array}$ & $\begin{array}{l}\text { A drug-eluting self-retaining Suture comprises a filament, a Plurality of retainers, and a drug } \\
\text { impregnated in or coated on the filament. The shape and distribution of retainers modifies the in } \\
\text { vivo release kinetics of the drug. The drug release kinetics may be modified uniformly or region } \\
\text { by region. The self-retaining Suture may for example be used for reattaching Severed nerves and } \\
\text { release nerve growth factor or other regeneration accelerating agents into the region of the nerve } \\
\text { injury. }\end{array}$ & Gross et al. (2013) \\
\hline
\end{tabular}




\section{Applications of Drug Eluting Sutures}

There is always requirement of novel drug eluting sutures modified with bioactive molecules (DNA, proteins, and growth factors), drugs, and antimicrobial agents to enhance the functional outcome of sutures. So, the drug eluting sutures can be utilized in various areas, including localized surgical site infections, wound healing, and ophthalmic drug delivery. The most common application of drug eluting suture is antimicrobial coated suture, silver coated sutures, or silver nanoparticle coated sutures. Recently, research is going on to develop stem cell seeded sutures to improve the functional utility of sutures in various chronic diseases.

\section{Future Prospective of Surgical Drug Eluting Sutures}

Although there are huge advancements and discoveries in the fields of material technology and surgical techniques, still the use of wound closures in the surgical procedures uses different types of sutures. The demand of these surgical sutures increases day by day because of increased number of surgical issues or procedures worldwide. The recent advancements and promising trends of sutures in the field of medical technology have huge potential in various clinical and surgical applications along with various specialized procedures and various methods of wound management. These sutures have been further modified and various active drugs have been included in these sutures. For example, when antimicrobial drugs were included in these sutures then they are named as "antimicrobial sutures," (Leaper et al., 2017) when anti-bacterial drugs were included in these sutures then they are named as "antibacterial sutures." Various other types of sutures have further been modified and used in medical technologies. Some example of these recently discovered sutures is as "drug eluting sutures," "bioactive sutures," "stem cells sutures," (Maruyama et al., 2016) "bioactive barbed sutures," "Simple barbed sutures," (Greenberg et al., 2013), and "elastic sutures."

The main function and efficacy of these recently discovered sutures mainly depends on physical and mechanical properties of these sutures. These sutures are modified/coated with one or more than one bioactive agents. These sutures should have better handling qualities. These sutures should be noncarcinogenic, non-toxic, and free of allergens. To meet all these important requirements, it is very necessary to pass these sutures after detailed pre-clinical trials and to evaluate the safety and efficacy of these sutures in human trials.

Smart suture threads are the recent area of invention which is able to collect diagnostic data. When these smart tissues penetrate into multiple tissue layers to intestinal fluids, they are able to collect the data regarding $\mathrm{pH}$ and glucose levels which are send to flexible wireless transmitter which is placed on human skin. With these smart sutures, multiple tissue suturing can be done in real time. Smart sutures seem to be as smart wearable system and efficient in implantable diagnostic devices.

\section{CONCLUSION}

The future aspect is to revolve a re-usable laparoscopic suturing device which enables the surgeons to use the new innovation in operating rooms and to reduce the some sutures related problems, such as skin irritation, delayed wound healing, and severe wound scarring. For manufacturing of sutures, various polymeric materials are available. However, biodegradable polymeric materials have received better attention for being used in manufacturing of biodegradable sutures. Biodegradable sutures offer various advantages in drug delivery as once inserted into the skin, they need not to be removed later. These sutures are very effective for the delivery of anti-inflammatory drugs and antibacterial agents to site of administration (wound area). Recently, researchers have developed sutures with better and improved mechanical as well as physical properties. Various efforts were made in analyzing the developments pertaining to active sutures for better drug delivery vehicle. The knotless barbed sutures are the current and emerging trend in the field of suture technology. These day antimicrobial sutures have also been discovered and used in wound healing. Some bio-active sutures, such as drug-eluting, electronic sutures, stem cells seeded sutures, and some other types of smart sutures have been discovered and used. These latest discovered strategies have expand the adaptability and usefulness of these sutures so that these can be used as physical entity to enable better delivery of drugs.

\section{CONFLICT OF INTEREST}

The authors declared that they have no conflicts of interest.

\section{FINANCIAL SUPPORT AND SPONSORSHIP}

None.

\section{ACKNOWLEDGMENT}

The authors would like to thank the Dr. Madhu Chitkara, Vice Chancellor, Chitkara University; Dr. Ashok Chitkara, Chancellor, Chitkara University; Dr. Sandeep Arora, Director, Chitkara College of Pharmacy for providing necessary facilities and support.

\section{REFERENCES}

Blaker JJ, Nazhat SN, Boccaccini AR. Development and characterisation of silver-doped bioactive glass-coated sutures for tissue engineering and wound healing applications. Biomaterials, 2004; 25(7-8):1319-29.

Blakney AK, Krogstad EA, Jiang YH, Woodrow KA. Delivery of multipurpose prevention drug combinations from electrospun nanofibers using composite microarchitectures. Int J Nanomed, 2014; 9:2967.

Blanco MG, Franco L, Puiggali J, Rodríguez-Galán A. Incorporation of triclosan into polydioxanone monofilaments and evaluation of the corresponding release. J Appl Polym Sci, 2009; 114(6): 3440-51.

Bölgen N, Vargel I, Korkusuz P, Menceloğlu YZ, Pişkin E. In vivo performance of antibiotic embedded electrospun PCL membranes for prevention of abdominal adhesions. J Biomed Mat Res B Appl Biomater 2007; 81(2):530-43.

Casalini T, Masi M, Perale G. Drug eluting sutures: a model for in vivo estimations. Int J Pharm, 2012; 429(1-2):148-57.

Catanzano O, Acierno S, Russo P, Cervasio M, De Caro MD, Bolognese A, Sammartino G, Califano L, Marenzi G, Calignano A, Acierno D. Melt-spun bioactive sutures containing nanohybrids for local delivery of anti-inflammatory drugs. Mater Sci Eng C, 2014; 43:300-9.

Champeau M, Thomassin JM, Tassaing T, Jérôme C. Drug loading of polymer implants by supercritical $\mathrm{CO}_{2}$ assisted impregnation: a review. J Control Rel, 2015; 209:248-59.

Champeau M, Thomassin JM, Tassaing T, Jérôme C. Current manufacturing processes of drug-eluting sutures. Expert Opin Drug Del, 2017; 14(11):1293-303. 
Chen DW, Hsu YH, Liao JY, Liu SJ, Chen JK, Ueng SW. Sustainable release of vancomycin, gentamicin and lidocaine from novel electrospun sandwich-structured PLGA/collagen nanofibrous membranes. Int J Pharm, 2012; 430(1-2):335-41.

Chen X, Hou D, Tang X, Wang L. Quantitative physical and handling characteristics of novel antibacterial braided silk suture materials. J Mech Behav Biomed Mat, 2015a; 50:160-70.

Chen X, Hou D, Wang L, Zhang Q, Zou J, Sun G. Antibacterial surgical silk sutures using a high-performance slow-release carrier coating system. ACS Appl Mat Interfaces, 2015b; 7(40):22394-403.

Chou SF, Carson D, Woodrow KA. Current strategies for sustaining drug release from electrospun nanofibers. J Control Rel, 2015; 220:584-91.

Cichocki Jr FR. Fluid emitting suture needle. United State Patent US 20050070959 A1, 2005.

Cohen M. Antimicrobial sutures and methods of making them. United State Patent US 20070010856A1, 2007.

Colombo G, Padera R, Langer R, Kohane DS. Prolonged duration local anesthesia with lipid-protein-sugar particles containing bupivacaine and dexamethasone. J Biomed Mat Res B Appl Biomater, 2005; 75(2):458-64.

Cummings SH, Grande DA, Hee CK, Kestler HK, Roden CM, Shah NV, Razzano P, Dines DM, Chahine NO, Dines JS. Effect of recombinant human platelet-derived growth factor-BB-coated sutures on Achilles tendon healing in a rat model: a histological and biomechanical study. J Tissue Eng, 2012; 3(1):2041731412453577.

Dennis C, Sethu S, Nayak S, Mohan L, Morsi Y, Manivasagam G. Suture materials - current and emerging trends. J Biomed Mat Res A, 2016; 104(6):1544-59.

Elsner JJ, Zilberman M. Antibiotic-eluting bioresorbable composite fibers for wound healing applications: microstructure, drug delivery and mechanical properties. Acta Biomaterialia, 2009; 5(8): 2872-83.

García-Vargas M, González-Chomón C, Magariños B, Concheiro A, Alvarez-Lorenzo C, Bucio E. Acrylic polymer-grafted polypropylene sutures for covalent immobilization or reversible adsorption of vancomycin. Int J Pharm, 2014; 461(1-2):286-95.

Gariepy TP. The introduction and acceptance of Listerian antisepsis in the United States. J History Med Allied Sci, 1994; 49(2): 167-206.

Geiger BC, Nelson MT, Munj HR, Tomasko DL, Lannutti JJ. Dual drug release from $\mathrm{CO} 2$-infused nanofibers via hydrophobic and hydrophilic interactions. J Appl Polym Sci, 2015; 132 (38):42571.

Greenberg JA, Goldman RH. Barbed suture: a review of the technology and clinical uses in obstetrics and gynecology. Rev Obstet Gynec, 2013; 6(3-4):107.

Gross JM, Drubetsky L, Naimagon A, Avelar R, D'agostino WL, Nelson KD, Crow BB, Griffin NB, inventors; Ethicon Inc, Ethicon LLC, assignee. Drug-eluting self-retaining sutures and methods relating thereto. United States patent US 20130317545A1, November 2013.

He CL, Huang ZM, Han XJ. Fabrication of drug-loaded electrospun aligned fibrous threads for suture applications. J Biomed Mat Res A, 2009; 89(1):80-95.

Hu W, Huang ZM, Liu XY. Development of braided drug-loaded nanofiber sutures. Nanotechnol, 2010; 21(31):315104.

Huh BK, Kim BH, Kim SN, Park CG, Lee SH, Kim KR, Heo CY, Choy YB. Surgical suture braided with a diclofenac-loaded strand of poly (lactic-co-glycolic acid) for local, sustained pain mitigation. Mat Sci Eng C, 2017; 79:209-15.

Hyde RA, Jung EKY, Myhryold NP, Tegreene CT, Wattenburg WH, Wood LL, Zare RN. Invention Science Fund I LLC. Vasculature and lymphatic system imaging and ablation associated with a reservoir. United State Patent US Patent 2012 8285367, 2012.

John AT. Triclosan containing absorbable sutures with extended antimicrobial properties. United State Patent US 2004/0185250 A1, September2004.
Kashiwabuchi F, Parikh KS, Omiadze R, Zhang S, Luo L, Patel HV, Xu Q. Development of absorbable, antibiotic-eluting sutures for ophthalmic surgery. Transl Vis Sci Technol, 2017; 6(1):1.

Kenawy ER, Bowlin GL, Mansfield K, Layman J, Simpson DG, Sanders EH, Wnek GE. Release of tetracycline hydrochloride from electrospun poly (ethylene-co-vinylacetate), poly (lactic acid), and a blend. J Control Rel, 2002; 81(1-2):57-64.

Labhasetwar V, Bonadio J, Goldstein S, Chen W, Levy RJ. A DNA controlled- release coating for gene transfer: Transfection in skeletal and cardiac muscle. J Pharm Sci, 1998; 87(11):1347-50.

Leaper D, McBain AJ, Kramer A, Assadian O, Sanchez JL, Lumio J, Kiernan M. Healthcare associated infection: novel strategies and antimicrobial implants to prevent surgical site infection. Ann R Coll Surg Engl, 2010; 92(6):453-8.

Leaper D, Wilson P, Assadian O, Edmiston C, Kiernan M, Miller A, Bond-Smith G, Yap J. The role of antimicrobial sutures in preventing surgical site infection. Ann R Coll Surg Engl, 2017; 99(6):439-43.

Lee DH, Kwon TY, Kim KH, Kwon ST, Cho DH, Jang SH, Son JS, Lee KB. Anti-inflammatory drug releasing absorbable surgical sutures using poly (lactic-co-glycolic acid) particle carriers. Polym Bull, 2014 71(8):1933-46.

Lee JE, Park S, Park M, Kim MH, Park CG, Lee SH, Choi SY, Kim BH, Park HJ, Park JH, Heo CY. Surgical suture assembled with polymeric drug-delivery sheet for sustained, local pain relief. Acta Biomaterialia, 2013; 9(9):8318-27.

Lee JS, Lu Y, Baer GS, Markel MD, Murphy WL. Controllable protein delivery from coated surgical sutures. J Mat Chem, 2010; 20(40):8894-903.

Loh A. Controlled release of drugs from surgical suture. Doctoral dissertation, Massachusetts Institute of Technology, 1987.

Mack BC, Davis ME, Wright KW. Layered drug delivery polymer monofilament fibres. United State Patent US 20090 155326A1, June 2009.

Maruyama T, Jeong J, Sheu TJ, Hsu W. Stem cells of the suture mesenchyme in craniofacial bone development, repair and regeneration. Nat Commun, 2016; 7:10526.

Meinel AJ, Germershaus O, Luhmann T, Merkle HP, Meinel L. Electrospun matrices for localized drug delivery: current technologies and selected biomedical applications. Eur J Pharm Biopharm, 2012; 81(1):1-3.

Ming $\mathrm{X}$, Nichols $\mathrm{M}$, Rothenburger $\mathrm{S}$. In vivo antibacterial efficacy of Monocryl plus antibacterial suture (Poliglecaprone 25 with triclosan). Surg Infect (Larchmt), 2007; 8(2):209-14.

Ming X, Rothenburger S, Nichols MM. In vivo and in vitro antibacterial efficacy of PDS plus (polidioxanone with triclosan) suture Surg Infect (Larchmt), 2008; 9(4):451-7.

Modak S, Sampath L. Columbia University of New York Triclosan-containing medical devices. United State Patent US19985772640, 1998.

Morizumi S, Suematsu Y, Gon S, Shimizu T. Inhibition of neointimal hyperplasia with a novel tacrolimus-eluting suture. J Am Coll Cardiol, 2011; 58(4):441-2.

Mysore V. ACS (I) textbook on cutaneous and aesthetic surgery. Jaypee Brothers Medical Publishers, New Delhi, India, 2012.

Nagy ZK, Balogh A, Drávavölgyi G, Ferguson J, Pataki H, Vajna B, Marosi G. Solvent-free melt electrospinning for preparation of fast dissolving drug delivery system and comparison with solvent-based electrospun and melt extruded systems. J Pharm Sci, 2013; 102(2):508-17.

Parikh PM, Davison SP, Higgins JP. Barbed suture tenorrhaphy: an ex vivo biomechanical analysis. Plast Reconstr Surg, 2009; 124(5):1551-8.

Pelz K, Todtmann N, Otten JE. Comparison of antibacterialcoated and non-coated suture material in intraoral surgery by isolation of adherent bacteria. Ann Agric Environ Med. 2015; 22(3):551-5.

Perale G, Casalini T, Barri V, Müller M, Maccagnan S, Masi M. Lidocaine release from polycaprolactone threads. J Appl Polym Sci, 2010 117(6):3610-4 
Ray JA, Doddi N, Regula D, Williams JA, Melveger A. Polydioxanone (PDS), a novel monofilament synthetic absorbable suture. Surg Gynecol Obstet, 1981; 153(4):497-507.

Rodeheaver GT, Kurtz LD, Bellamy WT, Smith SL, Farris H, Edlich RF. Biocidal braided sutures. Arch Surg, 1983; 118(3):322-7.

Rooney A. The story of medicine. Arcturus Publishing Ltd, London, UK, 2009

Rothenburger S, Spangler D, Bhende S, Burkley D. In vitro antimicrobial evaluation of Coated VICRYL* Plus Antibacterial Suture (coated polyglactin 910 with triclosan) using zone of inhibition assays. Surg Infect, 2002; 3(S1):s79-87.

Rowland SM, Uman IJ, Cottone Jr. Drug eluting implantable medical device. United State Patent US 20040039441 A1, February 2004. 23(6):327-34

Saber A. Ancient Egyptian surgical heritage. J Invest Surg, 2010;

Scaffaro R, Botta L, Sanfilippo M, Gallo G, Palazzolo G, Puglia AM. Combining in the melt physical and biological properties of poly (caprolactone) and chlorhexidine to obtain antimicrobial surgical monofilaments. Appl Micro Biotechnol, 2013; 97(1):99-109.

Shalaby SW. Antimicrobial, synthetic, fibrous and tubular medical devices. United State Patent US 20040171323a1, September 2004.

Shibuya TY, Kim S, Nguyen K, Do J, McLaren CE, Li KT, Chen WP, Parikh P, Wadhwa A, Zi X, Chen VY. Bioactive suture: a novel immunotherapy for head and neck cancer. Clin Cancer Res, 2004; 10(20):7088-99.

Shibuya TY, Kim S, Nguyen K, Parikh P, Wadhwa A, Brockardt C, Do J. Covalent linking of proteins and cytokines to suture: Enhancing the immune response of head and neck cancer patients. Laryngoscope, 2003; 113(11):1870-84.

Shibuya TY, Wei WZ, Zormeier M, Ensley J, Sakr W, Mathog RH, Meleca RJ, Yoo G, June CH, Levine B, Lum LG. Anti-CD3/anti-CD28 monoclonal antibody-coated suture enhances the immune response of patients with head and neck squamous cell carcinoma. Arch Otolaryngol Head Neck Surg, 1999; 125(11):1229-34.

Shukla A, Fuller RC, Hammond PT. Design of multi-drug release coatings targeting infection and inflammation. J Control Rel, 2011; 155(2):159-66.

Singh H, Tyagi PK. Radiation induced grafting of methacrylic acid onto silk for the immobilization of antimicrobial drug for sustained delivery. Die Angewandte Makromolekulare Chemie: Appl Macromol Chem Phy, 1989; 172(1):87-102.

Sugiura K, Ogawa S, Tabata I, Hori T. Impregnation of tranilast to the poly (lactic acid) fiber with supercritical carbon dioxide and the release behavior of tranilast. Sen'i Gakkaishi, 2005; 61(6):159-65.

Thimour-Bergström L, Roman-Emanuel C, Scherstén H, Friberg Ö, Gudbjartsson T, Jeppsson A. Triclosan-coated sutures reduce surgical site infection after open vein harvesting in coronary artery bypass grafting patients: a randomized controlled trial. Eur J Cardiothorac Surg, 2013; 44(5):931-8.

Viju S, Thilagavathi G. Characterization of tetracycline hydrochloride drug incorporated silk sutures. J Text Inst, 2013; 104(3): 289-94.

Wang L, Chen D, Sun J. Layer-by-layer deposition of polymeric microgel films on surgical sutures for loading and release of ibuprofen. Langmuir, 2009; 25(14):7990-4

Weldon CB, Tsui JH, Shankarappa SA, Nguyen VT, Ma M, Anderson DG, Kohane DS. Electrospun drug-eluting sutures for local anesthesia. J Control Rel, 2012; 161(3):903-9.

Wu DQ, Cui HC, Zhu J, Qin XH, Xie T. Novel amino acid based nanogel conjugated suture for antibacterial application. J Mater Chem B, 2016; 4(15):2606-13.

Wu MH, Poncet P. Medical devices having drug eluting properties and methods of manufacture thereof. United State Patent US 20040193257, September 2004.

Zamani M, Prabhakaran MP, Ramakrishna S. Advances in drug delivery via electrospun and electrosprayed nanomaterials. Int J Nanomed, 2013; 8:2997.

Zhukovskii VA, Khokhlova VA, Korovicheva SY. Surgical suture materials with antimicrobial properties. Fibre Chem, 2007; 39(2):136-43.

Zurita R, Puiggalí J, Rodríguez-Galán A. Loading and release of ibuprofen in multi-and monofilament surgical sutures. Macromol Biosci, 2006a; 6(9):767-75.

Zurita R, Puiggalí J, Rodríguez-Galán A. Triclosan release from coated polyglycolide threads. Macromol Biosci, 2006b; 6(1):58-69.

\section{How to cite this article:}

Anureet AA, Geeta GA, Janita JC, Param PM, Manju MN. Drug eluting sutures: A recent update. J Appl Pharm Sci, 2019; 9(07):111-123. 